\title{
WHAT ARE THE POTENTIAL END CUSTOMERS OF THE HEAT MARKET LIKE?
}

THE CUSTOMER SEGMENTATION CHALLENGE ON THE HEAT MARKET

Due to the increasing role of the digitalization and the emergence of new consumption patterns, end customers became empowered decision makers. They show the tendency to trust less the professionals and rather consult their social environment by their purchase decisions. As a consequence, marketers - who apply a 2-step sales strategy, by focusing on the professionals at the first place - are challenged in their customer segmentation. It is essential for marketers to get a deeper insight into the underlying motives and motivators behind the end customer attitude towards heating products, as installers fulfill less and less the mediator role in the purchase process between end customers and heating manufacturers.

In this paper the authors treat the heating market as a special case, where they put the end customers in the focus of the research - instead of the heating technology they adopt - and investigate the characteristics of the potential end customers, their needs, expectations and purchase motivation. The authors carried out a two-step explorative research with homeowners in Hungary, which they consider as the first step in the investigation of the end customer characteristics from a marketing managerial approach. The results show that in general end customers are mainly driven by financial and functional factors in their customer behavior and plan the purchase deliberately instead of facing and emergency situation, which means that heating manufacturers have a lead time to reach end customers with tailored offers. ${ }^{1}$

\section{Keywords: end customer characteristics, purchase process, customer behavior, heat market}

$\mathrm{T}$ he building industry is affected by several aspects due to diverse EU directives and legislations on one side and the change in the consumption pattern of individuals and households on the other side. The heat market ${ }^{2}$ merges the characteristics of end customers' demand for an optimal room climate with the influencing role of installers and the interest of manufacturers, and the diverse governmental, political and legal measures that set the framework for today's market operation.

Due to the complex market mechanism, the high technology intensity and investment characteristic (bought for 15-20 years) of the heating products, the numerous heating brands with low differentiation and the compulsory governmental regulations all mean that the installer - as mediator stakeholder - is an essential participant of the value chain.

To overcome this barrier, heating manufacturers built up a 2-step sales strategy, where manufacturers sell heating products via installers to end customers. Despite the fact that end customers are the paying customers and final product users at the same time, manufacturers have less or no direct contact to them, which is in itself a paradox situation (Wüstenhagen et al., 2008).

\footnotetext{
1 Acknowledgement

The authors gratefully acknowledge the financial support from Bosch Thermotechnik GmbH. for facilitating an international quantitative research with end customers on the heat market.

2 The heat market refers to the part of the HVAC (Heating, Ventilation and Air Conditioning) market, where manufacturers produce and sell heating technology to customers to ensure indoor temperature and warm water comfort. This paper refers to the residential heat market, where heating products (heat generator appliances or boilers) are sold to single households. In this study all types of heat generating appliances are considered, regardless of fuel type and energy sources.
}

To increase efficiency, manufacturers focus on establishing a stable and loyal partnership with installers and other professional stakeholders (e.g. architects, planners, energy consultants, etc.) to make product recommendations to end customers, as the convincing voice of the manufacturers' technologies and brands. This strategical approach leads to a fragmented target group approach and to a customer segmentation challenge at the same time, where manufacturers are focusing primarily on the installers and consider them as their prior paying customers, however the end customers are the final users of the heating products. Based on this approach, manufactures drive their sales and marketing strategy, fragmented between more stakeholders, with less or no emphasis to the end customers at the same time.

Meanwhile, according to the latest megatrend researches, end customer behavior and consumption pattern is going through an elemental change, which heating manufacturers shouldn't disregard. The emergence of the virtual business processes (connectivity, e-commerce), the increasing role of health consciousness (the appearance of new health styles, health-techs, etc.), the new consumption patterns (sustainable consumption, hybrid consumption) the pressure of time (willingness to pay an extra charge for a better and faster service and execution) all influence the customers' environment and result in the change of end customer purchase attitude and decision-making pattern (Rauch et al., 2010; z-Punkt GmbH Foresight Company, 2008).

According to our opinion, the digital revolution and the still emerging role of the Internet - that has a great impact on the end customers' behavior and decision- 
making pattern- challenges the todays' segmentation approach of heating manufacturers: users acquire, share and exchange information with other users all around the World. As a result, end customers are not spending time anymore with consulting with professionals in stores but taking time to search on the Internet learning about products. As Wang et al. (2013, p. 337.) sees: "individuals are relying more on the members of their social network to influence and guide their purchase intentions instead of relying only on authority, experts, professionals, classic media and mass advertising". End customers conduct social search, which is a "process of finding information online, with the assistance of social sources (e.g. family, friends or unknown person)" (Morris et al., 2010). The reason behind this modified information search behavior is the increasing role of social networks in the decisionmaking process and the complex nature of the product.

But what does this mean for the heat market? As the end users of the products (the end customers) are empowered as active decision-makers - as they are turning to their social environment (other users of the products) to exchange information instead of consulting professionals along the purchase process - manufacturers mustn't leave end customers out of sight in the future as now they do.
As Bartels et al. (2006) argues, the recommendation of installers is not always corresponding the demand of the end customers; furthermore it might mislead end customers with advices that are "not to maximize their utility". Based on this asymmetry, if manufacturers want to be a part of the market competition by fulfilling market demand and increasing market share, they have to shift the focus and resources of their sales and marketing strategy from professionals directly to their paying end customers. For manufacturers it is essential to understand their end customers, their attitude towards heating products in the whole product lifecycle (from purchase to use) to offer tailored solutions that worth talking about in their social environment.

We consider the empowerment of end customers as a call for manufacturers and other marketers to consider the adaptation of their segmentation strategies on a practical level and as a research gap to fill in the scientific literature of the heat market. As only a very limited set of former researches put focus on the description of the end customers, in the first step this paper attempts to carry out an explorative research, to investigate the end customer needs, attitudes and underlying motivation of the purchase of a heating product from a marketing managerial point of view. Our goal is to get a first insight how the end customers are like that heating manufacturers know so less of.

Table 1.

Review of former scientific models based on end customer decision-making with heating products

\begin{tabular}{|c|c|c|}
\hline Researcher & Model & Technology \\
\hline Stolyarova et al. (2015) & $\begin{array}{l}\text { Choice experiment, household prefer- } \\
\text { ences, (willingness to pay) }\end{array}$ & All heating systems \\
\hline Qiu et al. (2014) & $\begin{array}{l}\text { Diffusion model, role of perceived } \\
\text { risk }\end{array}$ & $\begin{array}{l}\text { Energy efficient household appliances, installation of energy } \\
\text { efficient retrofit technologies }\end{array}$ \\
\hline Rouvinen (2013) & Choice experiment & Wood-pellet heating systems \\
\hline Philips (2012) & Choice experiment & Heating upgrade measures \\
\hline Achtnicht (2011) & Choice experiment & Energy efficiency measures, innovative heating systems \\
\hline Christie et al. (2011) & Adoption model, social influence & Energy efficient technologies, solar water heaters \\
\hline Claudy et al. (2011) & Diffusion model, willingness to pay & Microgeneration technologies \\
\hline Sopha et al. (2011) & Diffusion model & Wood-pellet systems \\
\hline Farsi (2010) & Choice experiment & Energy efficiency systems \\
\hline Kwak (2010) & Choice experiment & Heating renovation measures \\
\hline Mahapatra et al. (2010) & $\begin{array}{l}\text { Diffusion of innovative heating sys- } \\
\text { tems technology, customer needs and } \\
\text { attitudes }\end{array}$ & $\begin{array}{l}\text { Innovative heating systems, comprised of bedrock heat } \\
\text { pump, district heating, wood-pellet boiler }\end{array}$ \\
\hline Scarpa (2010) & Diffusion, willingness to pay & Micropower systems \\
\hline Tapaninen (2009) & Diffusion model & Wood-pellet systems \\
\hline Banfi (2008) & Choice experiment & Energy efficiency systems \\
\hline Caird et al. (2008) & Adoption model & Renewable energy systems \\
\hline Mahapatra et al. (2008) & Diffusion model & $\begin{array}{l}\text { Innovative heating systems: district heating, heat pump, } \\
\text { wood-pellet boilers }\end{array}$ \\
\hline Wüstenhagen et al. (2008) & $\begin{array}{l}\text { Diffusion of innovation, from adopter } \\
\text { point of view }\end{array}$ & Micropower systems \\
\hline Mahapatra et al. (2007) & Diffusion of bioenergy systems & Wood-pellet boilers \\
\hline Keirstead (2007) & Diffusion model & Photovoltaic systems \\
\hline Mallett et al. (2007) & Adoption model (social acceptance) & Solar water heaters \\
\hline Faiers et al. (2006) & $\begin{array}{l}\text { Diffusion model, influencing role of } \\
\text { grants }\end{array}$ & Solar power systems \\
\hline Kaplan (1999) & Diffusion model & Photovoltaic systems \\
\hline
\end{tabular}




\section{Literature overview}

As Table 1 presents, only a limited set of studies investigated the heat market, where end customers were involved by making a decision (for purchase or adoption) for a novel heating technology. All of these choice experiment models approached from the heating technology perspective, where the success of adoption was investigated by the identification of the most relevant influencing factors that affected adopters along the diffusion process. We found that former studies focused on the diffusion of innovative heating products (e.g. micropower systems, Wüstenhagen et al., 2008; wood-pellet systems, Mahapatra, 2007; Rouvinen et al., 2013, solar water heaters, Mallett, 2007; Christie et al., 2011), investigated the customers' willingness to pay for energy efficient measures and novel heating technologies (Kwak et al., 2010; Claudy et al., 2011; Scarpa et al., 2010), analyzed their risk perception (Qiu et al., 2014), etc. The common point of view in all these researches presented in Table 1 is that they considered the end customers as adopters/ non-adopters of a specific, innovative heating technology that has to be sold on the heat market. Furthermore, these researches treated the description of the end customers as a side effect of the choice and adoption models. This leads to the conclusion that the identified end customer characteristics by adopting e.g. heat pumps might not be applicable for the end customers, who prefer to stay with conventional / condensing gas boilers or for those, who adopt e.g. wood-pellet systems.

Only the minority of former researches identified some end customer characteristics and highlighted their specific needs, still only as a side topic of diffusion models. For this reason, we found only a very limited set of studies that dealt with the description of end customers and can be linked to the segmentation strategy of end customers.

Already in his earlier study, Stern (1985) tried to describe customers of energy efficiency decisions (not specifically for heating renovation) and found that they are not only rational economic actors, but energy users, who are:

- investors and willing to maximize their net financial value over a long term,

- consumers, whose choice reflect desires for personal benefits that are not financial,

- people, who are expressing personal attitudes and social values,

- people, who reflect the influence of friends and associates,

- consumers, who want to minimize effort and avoid future problems and inconveniences.

Stern emphasized the relevance of the financial and functional factors in the customer characteristics, furthermore the importance of the social environment (face-to-face communication of family, friends and other social contacts) in their decisions regarding energy efficiency, but not explicit to the end users of heating products.
In his later study Stern (2014, p. 43.) broadened the characteristics of end customers based on their energy choices that affect their household, such as:

- the place of living (where the household members work, shop, go to school, etc.),

- the choice of the home with its energy demand (with its size for space heating, the energy efficiency of the appliances, such as installed heating, etc.),

- the purchase of major appliances and the decision on energy efficiency improvements.

In this sense, end customers make a decision by choosing their homes according to the energy demand; they are willing to pay for the heating. In our opinion this supports the long-term investment characteristic of the purchase decision of heating products, but might not bring manufacturers closer to understand the mindset of their end customers.

We found some former researches that segmented end customers into different groups by identified factors in their characteristics. Sernhed (2008) investigated the energy supply of utilities to end customers (regarding district, electric heating and water heating systems) on the Swedish market. She argued that households in energy environment can't be considered as homogenous group of customers, households of district heating differ in their:

- socio-demographic factors (e.g. age, income, education and age of house),

- physical factors (e.g. living space, current heating device, age of boiler, etc.).

Furthermore, Sernhed (2008) found that district heating suppliers don't use the opportunity to collect information and to describe their potential customers based on diverse social factors, rather by the physical factors. This study also pointed on the fact that companies - in this case heat suppliers - don't deal with the social factors of end customers characteristics, their needs and attitudes based on they might offer specific, tailored services.

Michelsen et al. (2013) researched the underlying motivation behind the adoption of diverse residential heating systems (conventional versus innovative heating technologies) and clustered the potential end customers into the following groups, based on the adopted heating technology:

- convenience-oriented customers: the largest group of customers, who care more about comfort and less about economic factors in favor of the sustainability of their habits; they are more likely to stay at the conventional heating technology,

- consequence-aware customers: they are adopters of new technologies, considering financial benefits and costs and long-term consequences (e.g. energy prices and sustainable lifestyle); they are willing to purchase on the basis of energy efficiency, choosing innovative heating systems, such as pellet boilers or wood burning appliances, 
- multilaterally motivated customers: they consider aspects from both other clusters mentioned above: comfort must be paired with financial benefits and long-term consequences. Each factor is not equally important; relevance depends on the individual. Heat pumps and wood burning appliances are mostly chosen in this cluster.

This study also approaches from the adoption of diverse heating technologies and offers an end customer segmentation based on their innovativeness with heating technologies. They differed the rather conservative customers (comfort oriented and care less about economic factors), who stay with conventional heating technologies from the rather innovative customers (open for new heating technologies, they are triggered by financial benefits and energy efficiency, on a long-term) who adopted the novel technologies. They found that most of the customers are described by the convenience-oriented characteristics.

Wüstenhagen et al. (2008) identified 3 different end customer segments by the adoption of green energy products. They differed the dark-green customers (potential customers for all types of eco-innovations, who are ready to adopt technologies with higher operation costs and special fuel types) from light-green customers (ready to adopt environmental sound products with higher initial and operating costs if the perceived benefits are clear) and mainstream customers (not interested in environmental issues, they are adopting simple products or conventional technologies). This approach emphasizes the difference between customers based on their sensitivity regarding financial factors.

The above presented segmentation approaches share the common view that the identified end customer relation to heating (underlying motivation for purchase, needs, heating habits, etc.) and market the products and heating technologies that maximize their utility. We consider this approach as a gap in the scientific literature of heating products and a potential research area from a marketing managerial point of view.

\section{Theoretical framework}

As already mentioned in the literature overview section, we found only a very limited set of corresponding former researches that deals with the characterization of end customers of heating products, but dependent of the heating technology to be adopted. In this sense, there weren't any former constructs, theoretical frameworks and models we could have relied on by building our theoretical framework, or based on which we could have formulated propositions or testable hypothesis.

In order to organize and to structure the characteristics of potential end customers of the heat market - based on which an explorative survey empirical survey could be conducted - we reverted to the fundamental "7 O" marketing model of Kotler (1998), presented in Figure 1. We consider this classic marketing model - in default of any other frameworks or constructs we could have relied on - as a starting point, along which the initial assumptions of end customer characteristics could have been set up. However, the detailed description of the heat market (organization) and the special characteristics of the heating products (objects), furthermore the decisionmaking process of end customers (operation) are important elements of understanding the end users of heating products, this paper is not treating these fields of work as we want to keep our focus on the specific end customer characteristics.

Field of works in the end customer characterization
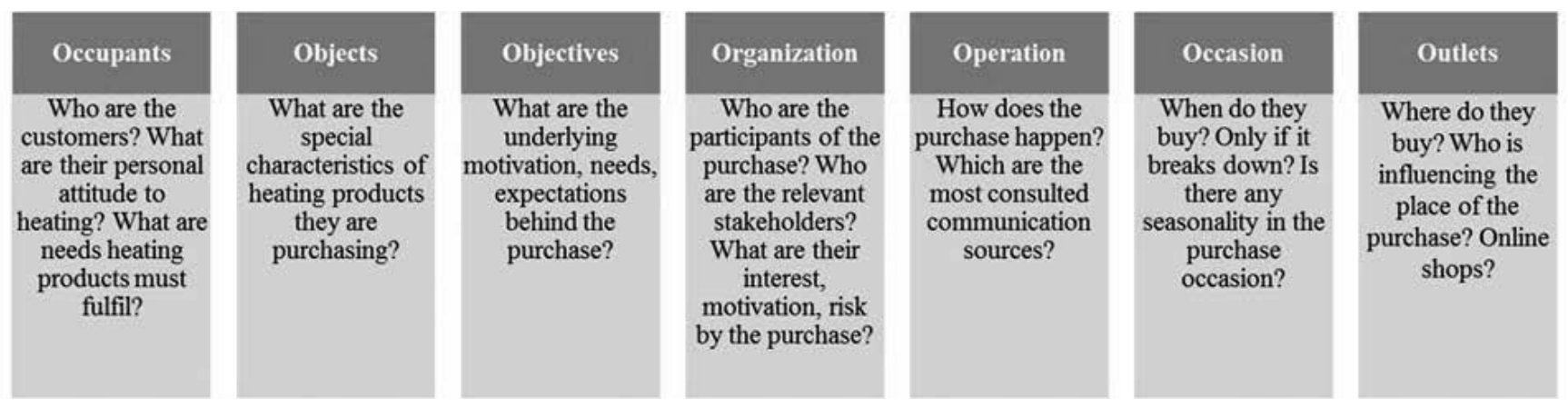

characteristics are varying by the product (technology) they were investigating. This means that the end customer characteristics might be applicable only for the adopters of the same heating technology. According to this approach, manufacturers should segment their end customers based on the heating technologies that have to be pushed for sales on the heat market.

In our opinion, heating manufacturers should approach from the end customers at first by understanding their
Occupants. According to the latest consumption trends, end customers are trying to achieve a more sustainable lifestyle, which leads to the emergence of the LOHAS customer group. LOHAS stands for Lifestyle of Health and Sustainability, and is a market segment focused on health and fitness, the environment, personal development, sustainable living and social justice. (LOHAS Group, 2010) The LOHAS Group (2010) defined six market sectors for this new customer segment: besides personal health, 
eco-tourism, alternative transportation, natural lifestyle and alternative energy, the segment of green buildings (importance of home certification, energy star appliances, sustainable flooring, renewable energy systems, wood burning alternatives, etc.) is also playing a role in the modern consumption. Furthermore, according to Lehota et al. (2013) these customers inform themselves briefly before they make a purchase decision and they are ready to influence the opinion of their family and friends.

As heating products are closely related to energy consumption aspects and environmental consciousness (financial factors, energy efficiency, etc.) we assume that green building plays an important role in the lives of the end customers, furthermore the potential end customers of heating products could be described by (any of the following) LOHAS characteristics, defined by Cortese (2003):

- they worry about environment,

- they want products to be produced in sustainable way,

- they spend more money to advance what they see as their personal development,

- they are willing to pay a premium for products and services they considered sustainable.

Objectives. End customers are such final product users, who consider the purchase of heating products as investment decisions, heating technology must be reliable and energy efficient, technology on renewable energy must pay off (Wüstenhagen et al., 2008).

We assume that end customers are driven by financial factors, not only by the investment costs (purchase motivation) but also by the running costs (price of energy by the usage). Furthermore, we assume that further, not known financial factors could motivate end customers for purchase.

As Farsi (2010) emphasize the risk perception is the central element of energy efficient renovation measures, we assume that end customers perceive financial risk along the purchase (if the product is working properly, if quality problems occur, etc.) as they have to make a decision with a complex, unfamiliar technology. Claudy et al. (2011) found that end customers perceived social risk as they were insecure how adaptation of a new heating technology might be perceived by their social surroundings. As this finding refers to a certain innovative heating technology, we assume that in general end customers don't perceive social risk by the purchase process.

The complex purchase process and the diverse perceived risk factors might lead to the assumption that the heating products are high-involvement products, which means that heating products are carefully chosen by end customers, information is actively acquired and evaluated. As Wüstenhagen et al. (2008, p. 15.) argues, despite the fact that heating systems have high investment and operating costs, they evoke mainly functional expectations and the potential for emotional marketing has only been marginally explored. We assume that if only the high investment costs and the complex purchase process would be considered, then heating products would be high- involvement products. But if we consider the harmless operation phase, where only the functional needs should be satisfied, the heating products are low-involvement products. Based on this assumption, involvement of heating products might be understood in the situation, where the end customer is located. In this sense involvement of heating products might be situational, "which deals with specific situation that stimulate end customers to involve with products or services" (Rehman et al., 2012, p. 600.).

Occasion. When it comes to the question when and based on which motivation end customers purchase a certain heating technology, there are several aspects to be identified by former technology-centric adoption models. Some researchers found the socio-economic factors, such as aging (Mahapatra et al., 2008), household income (Kasanen et al., 1989), number of children (Wilhite et al., 1999) or economic factors such as high operation, maintenance and fuel costs (Mahapatra et al., 2008; Caird et al., 2008). Others emphasized the influence of energy saving from the perspective of environmental consciousness (Keirstead, 2007; Caird et al., 2008) or the motivating role of governmental subsidies and grants (Michelsen et al., 2013; Wallace et al., 2010). Other former models found that the breakdown of former heating product motivates end customers for purchase (Mahapatra et al., 2008; Hallin, 1989; Stolyarova et al., 2015). The findings vary by the kind of the heating technology that former researches were investigating.

Based on this limited set of former models, we assume that the occasion and the motivation for the purchase is linked to each other. This means that the occasion of the purchase happens rather in the heating season, where the heating products is breaking down or when end customers are facing the increasing heating costs and energy prices. Still, we think that end customers are such conscious decision-makers, who are planning the purchase of a heating product instead of facing an emergency purchase situation.

Outlets. Based on the conducted literature review, we found no former studies, which analyzed the most consulted place of purchase. Contrary to the leading role of the Internet, due to the complex nature of the heating products - we assume that end customers buy less in online shops, rather in professional stores, where they can consult professionals. Otherwise we assume that end customers purchase directly from the installers.

Based on the limited set of corresponding literature regarding the end customer characteristics, their drivers and underlying motivation for purchase, we initiated some pre-assumptions, presented in this section. We think that in the first step, an explorative research has to be conducted with end customers in order to reveal technology independent, end customer characteristics. This paper introduces the methodology and results of this research, which we consider as a first milestone and initial step in the investigation of end customer attitude towards heating products. 


\section{Methodology}

In the lack of corresponding scientific literature, we conceptualized assumptions but couldn't derive any prior hypothesis to validate as other classical researches do. This was the main reason and motivation to set up a 2-step explorative research with end customers in Hungary, where in the first step we conducted interviews with customers, in order to reveal specific characteristics and to get a deeper customer insight into the underlying motivations, needs, expectations based on the initial assumptions introduced in the previous section. Explorative research is appropriate when the problem needs to be defined more precisely, research questions or hypothesis developed (Malhotra, 2007). It should be followed by descriptive research, if the hypothesis should be tested (Malhotra, 2007). At the second step, based on the key findings of the in-depth interviews, we carried out a survey using online questionnaire to make quantitative assumptions regarding the special characteristics of potential end customer. Defining the research design we followed the sequential exploratory strategy (Creswell, 2009) starting with qualitative data collection and analysis, followed by a second phase of quantitative data collection and analysis that builds on the results of the first qualitative phase.

In total, we conducted 10 in-depth interviews with married couples. The respondents were chosen by the non-probability snowball technique, which ensured the selection of the relevant target group and excluded e.g. tenants (who made no purchase decision of heating products). The interviews were carried out in the homes of the respondents, which ensured a more pleasant atmosphere. The presence of the partner was essential as they made a joint-decision, which affected the whole household. Such projective techniques were applied as word association, autobiographical memories, choice ordering, third person technique or picture technique. During the interviews notes were made and the results were analyzed with the Nvivo 10 program.
At the second step, online questionnaire was conceptualized and the data collection was carried out on the Hungarian residential market with homeowners, aged over 18 and with Internet access. The targeted sample (online panel) was provided by Ipsos Interactive Services, the access to the panel was financially supported by Bosch Thermotechnik GmbH. The participants are self-recruited and agreed to participate in the questionnaire. The quality of the panel is verified and managed by the provider. The online panel itself represents people aged 18 with Internet access but it is impossible to ensure the representativeness of potential end customers, who are homeowners and willing to purchase a heating product in the coming 18 months. This is why we applied a screening section, just before the start of the questionnaire in order to filter the relevant target group. Participants (1) with ownership: house and/ or flat and (2) with intention to purchase a new heating product in the past/ coming 18 months were allowed to open the questionnaire at all, otherwise they were screened out. In total 1.163 potential customers participated in the survey by opening the questionnaire, thereof 643 participants were filtered out due to the initial screening questions. 520 participants opened the questionnaire, thereof 417 respondents completed until the end. The field work was carried out at the early heating season (November) as we learned from the in-depth interviews that seasonality plays an important role with heating products. In the questionnaire we used multi-item scales for the attitude towards heating and heating products, formulated based on literature and mainly on the results of the qualitative research. The items were to evaluate on a 5-point Likert scale. We measured the internal consistency reliability with the Cronbach's alpha, we have got for all the constructs consisting the multi-item scales a Cronbach's alpha value above 0,7 that shows a high level of reliability (Nunnally, 1978).

\section{Results: Qualitative research - In-depth interviews}

Respondents of the in-depth interviews are all owners of a house and/or a flat and made a purchase decision on their

End customer characteristics: lifestyle, values and attitude towards heating product,

Figure 2. purchase and its evaluation
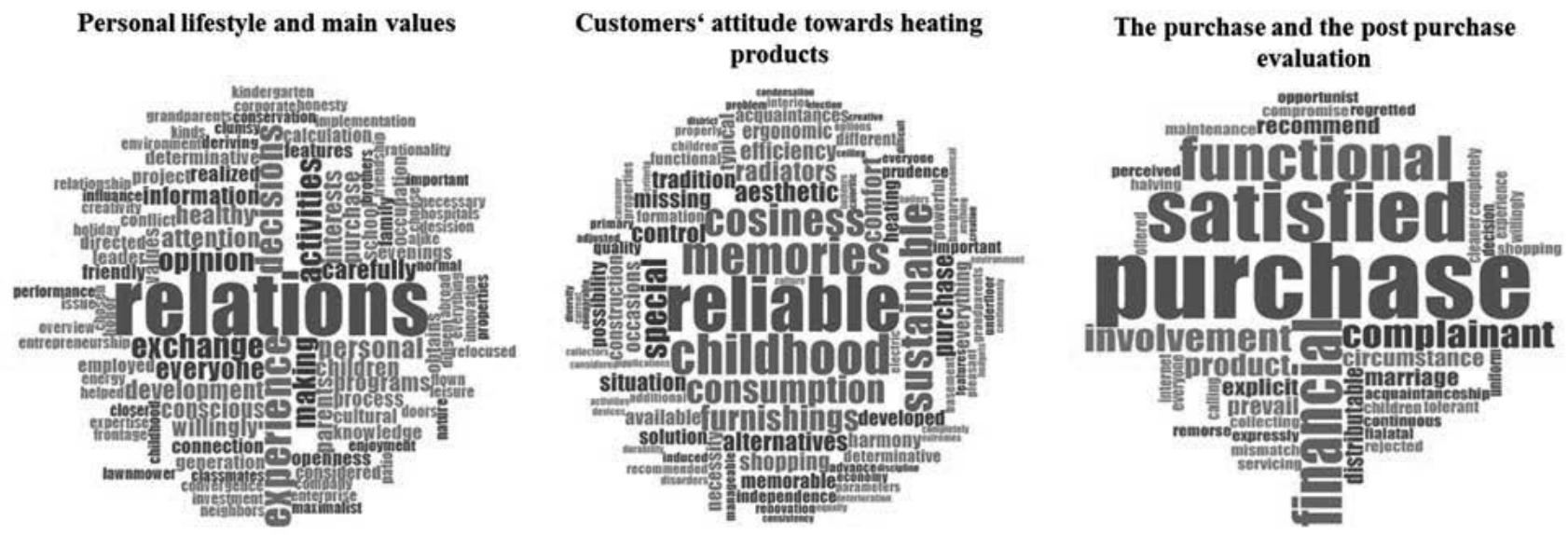
own with a heating product at least once in the past: either they bought a new heating system (due to new built) or renovated their existing heating system (by extending it with an alternative heating solution). In order to get to know the customers of the heat market, to get a deeper insight into their characteristics, behavior, expectations and attitudes towards the heating products, first of all respondents were asked about their personal lifestyle and main values, presented in Figure 2.

As the left element in Figure 2 shows, interviewees mentioned the importance of their relations with the people around them: with family, friends and their close social environment. In context with the purchase of the heating product it refers to a careful, joint-decision making that were made within the family or with the support of friends, as one couple said: "the exchange of opinion and experiences between brothers is important..." Some of the respondents have stable and lasting friendships, as one couple said: "there is an opinion leader in our circle of friends, who is very up-to-date and well informed about different topics and products".

The words conscious, careful, attention also may refer to the lifestyle of the respondents in context with their environment. Interviewees reported that they care about their personal health (nutrition and sports) and about their environment by conscious energy and gas consumption, waste separation, energy efficient household appliances, lightbulbs, walk or ride bike instead of using car, etc. As one couple said: "we do our best to live environmental conscious...". This refers to the LOHAS values that end customers are reported to be important in their lives.

In context with heating products respondents care about their energy consumption and sustainability (central element in Figure 2) by considering alternative heating solutions in case of heating renovations, like pellet boilers, tile stove, condensing boiler, etc. As one couple said: "we were thinking about to install a solar panel to use regenerative energy in order to reduce costs, but it was way too expensive and the return on investment wasn't reasonable". Respondents reported that green building (energy efficient and sustainable materials, products) are playing an important part in the renovation of their homes, but they are not willing to pay a premium price for these products, especially if they don't see the return of their investment. Furthermore, respondents reported that warmth and warm water comfort (their technical execution) plays an important role in living space. Respondents found it important that the heating should not ruin the interior design of the living space, but still it evokes mainly functional expectations. There was one couple who said: "if I could buy a stylish boiler I would place it in the living room..."

Due to the increasing energy prices (main energy source is gas, it has a good coverage but decreasing heating quality and it is expensive), respondents are not only looking for alternative heating solutions but they control their heating system by regulating the radiators if they are not at home or during the nighttime. The heating is turned on mainly at special occasions (family celebrations, Christmas, etc.) to make the house heated cozy and warm and the regulation is done by the respondent married couple. In our opinion this refers to the financial and functional factors (risks) respondents perceived by the use of the product. They are motivated to renovate the existing heating system with products that are easy to control and where the running costs can be held on an efficient level as they perceive the price of energy high.

The word childhood (central element in Figure 2) stands for the memories respondents recalled about heating products, as one couples said in context with energy efficiency and conscious energy consumption: "as an alternative solution we thought about the wood heating technology because the feeling of crackling fire reminded us of our childhood." Interviewees had no problem with preparing and refilling the boiler with wood or pellet, they saw it as a self-evident task that reminded them to their childhood. The word coziness and comfort (central element in Figure 2) refers to their homes and to the room climate, respondents expect from the heating product. It is not only about the warm water and the warmth, but the comfortableness and the security of supply, which means that end customers might expect from heating products to fulfill higher level of needs at the same time. We think that heating products fulfill not only physiological needs (warmth and warm water), but also safety (security of supply, home, family, etc.) and might fulfill or support needs for love and belonging (family, time spent together, comfort, special occasions etc.).

Interviewees were asked which of the following words they can associate to a new heating product, namely which expectations does a new heating product must fulfill. Diverse tastes, sounds, needs were specialized and the following characteristics were the mostly agreed: available, reliable, ergonomic, special occasions, aesthetical, trust, energetic, though, etc., which might refer to the product personality "competent" (reliable, intelligent, successful) that end customers associate to heating products (Aaker, 1997). ${ }^{3}$

Respondents were asked about their purchase attitude, particularly about their motivation for purchasing a new heating system (right element in Figure 2). As only one couple reported that their heating broke down and needed an urgent solution, other respondents deliberately planned their purchase (most of them perceived the need already the heating season before) that lasted 3-6 months long. The rising energy costs seemed to be the main motivation for the purchase, governmental subsidies were found to be less attractive due to the unfamiliar application process and the insecure outcome (if the application succeeds at all, amount of subsidy). Respondents conducted active information search and turned to diverse information sources (family, friends, online portals, blogs and forums,

\footnotetext{
3 According to Aaker $(1997$, p. 347.) the personality of a product or a brand ("set of human characteristics associated to a brand") enables consumers to express their (ideal or special) self. Aaker (1997) defined a brand personality framework with the following personality dimensions: sincerity (honest, down-to-earth, wholesome), excitement (daring, up-to-date, spirited), competence (reliable, intelligent, successful), sophistication (upper class, charming), ruggedness (tough, outdoorsy).
} 
installer, architect, etc.) for cross-checking the gained information, where online (social) sources played an important role.

Respondents found the purchase process complex and complicated, furthermore they perceived functional risk (if the new heating product will work properly, if it won't break down, if it can be regulated effectively, etc.) and financial risk (if the product worth its price, quality of a cheaper product, of an unknown brand, cost-efficiency, etc.) along the purchase process. None of the respondents agreed to perceive social risk along the purchase process or by the use of the product.

Regarding the place of the purchase, end customers purchased on their own looking for the best price alternative. None of the respondents purchased from the installer, but where the installer suggested. None of the participants purchased via online sources or online shops.

Interviewees showed different degrees of involvement depending on the circumstances or the situation they are at. are applicable. Green building prevails in heating renovation by energy efficient renovation or heating systems extension, but respondents are not willing to pay a premium price for sustainable products (important financial factor). Respondents reported to be conscious, active decision-makers turning to many information sources.

- Respondents recalled childhood memories with heating technologies, the learning process with heating products starts at the early age, which might influence their decision-making with certain technologies.

- Heating products might fulfill higher level of needs beyond physiological needs, such as safety needs or belonging.

- Financial factors prevail in the investment and running costs (regulation) of the heating products, in the increasing energy prices, the return on energy efficiency investments, furthermore in the available governmental subsidies.

\section{Perceived involvement in diverse situation along the product lifecycle}

Figure 3.

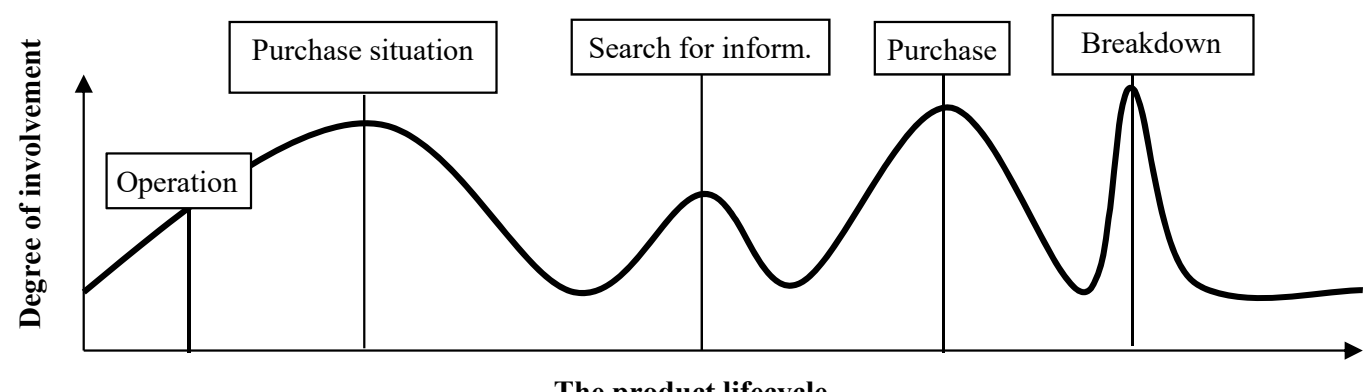

The product lifecycle

As Figure 3 shows, in the phase of harmless operation, respondents showed a low-involvement attitude as the heating product fulfilled the functional needs (warmth and warm water), however they might have realized the high energy costs and the inefficient operation. At the phase of purchase situation (decision is already made for a new heating product), by the intensive information search and validation respondents showed a higher degree of involvement by acquiring the right information from the most credible information sources. By the purchase phase, the perception of functional and financial risk evoked the high degree of involvement. Once the heating product is finally purchased, in the phase of operation the degree of involvement shows a lower degree again. In case of the couple, who reported the breakdown of the boiler, the involvement was suddenly very high to get the heating system repaired as fast as possible, since they had no warm water and heating for a couple days.

Based on the analysis of the results, the following key findings can be summarized, which we relied on by the conceptualization of the qualitative online questionnaire:

- Respondents are considering themselves environment conscious, most of the LOHAS characteristics
- Respondents perceive financial risks due to the increasing energy prices and functional risk regarding the unfamiliar complex technology.

- Respondents expect from a new heating product to be reliable, intelligent, available, etc. that might refer to the perceived product and brand personalities.

- Respondents deliberately planned their purchase due to the rising energy prices, governmental subsidies didn't trigger the purchase.

- A screening technique is required by the online questionnaire in order to reach the potential end customers of heating products. Purchase takes 3-6 months, need for a new heating can be perceived a heating season earlier.

\section{Results: Quantitative research - online survey}

Based on the key findings of the in-depth interviews, the online questionnaire was conceptualized to make quantitative ascertainments of end customer characteristics.

\section{Characteristics of the respondents in the sample} The average age of the Hungarian respondents were 37,8 years, where male respondents were represented by $56 \%$ and female respondents by $44 \%$ in the sample. $40 \%$ of the 
respondents have a marital status and live with their children in one household, single or young couple household are represented in the sample with the nearly the same extent (37\%). $7 \%$ of the respondents have a senior household, where children already moved out. The half of the respondents have a high school or secondary school certificate, $49 \%$ obtain a university degree $(1 \%$ reported to have no certificate).

Nearly $60 \%$ of the respondents bought their very first heating product in the past 5 years, $25 \%$ in the past $6-10$ years (17\% earlier than 10 years) and all respondents either bought a new heating product in the past 18 month or planning to do so in the coming 18 months. Regarding financial status, $73 \%$ of the respondents have a monthly household income below 150.000,- HUF and 49\% of the respondents reported to be under financial depth. Nevertheless $40 \%$ of the respondents are saving money for renovation and $38 \%$ have savings for emergency situations around the household.

As the results of the qualitative interviews showed, respondents considered themselves environmental conscious, which prevailed in more fields of their lives. At first, the LOHAS characteristics were checked on the qualitative sample, presented in Figure 4.

As results show, every fourth respondents said that they were health conscious, worry about environment and want products to be produced in a sustainable way. But when it comes to the willingness to pay a premium price for these products, only the minority of the respondents agreed. Except for alternative energy financing (e.g. renewable energy credits, green pricing) the majority of the respondents agreed that diverse attributes of LOHAS segments prevail in their lives: mostly in personal health (e.g.: natural and organic products, nutritional products, dietary supplements, etc.) and in natural lifestyle (indoor and outdoor furnishing, compact fluorescent lights, organic cleaning supplies, etc.). $54 \%$ of the respondents agreed that green building prevails in their lives in such fields as home certifications, energy star appliances, wood alternatives and renewable energy systems.
As the results of the qualitative interviews showed, end customers perceive certain needs and expectations towards heating products, we tested on a quantitative sample. Results show - presented in Figure 5 - that the majority of the respondents agreed that heating and warm water comfort plays a role in the interior design, which confirmed that heating products must not fulfill only functional needs but have to have an acceptable appearance when it is placed in the living space.

After that, respondents were asked about the level of needs that a heating product must fulfill in their lives. Respondents found rather important the security of supply and the health of the body (ranked on the first place), followed by the actual physiological needs (warmth, warm water). Higher level of needs such as coziness, comfort, and carefree stay at home are rather not important needs a heating product must fulfill. Otherwise if the heating would not work, warmth and warm water must be missed the most, security of supply is rather a less important need to be fulfilled.

Regarding the expectations towards the heating product, the majority of respondents (56\%) associate their optimal heating product as a competent, intelligent and successful person. In our opinion this means that respondents expect from the heating product an intelligent and reliable operation, where they perceive the security of the supply by fulfilling needs regarding comfort and financial factors.

We learned from the interviews with married couples that they created their own heating rituals, mainly based on energy efficiency and cost saving. The heating system must be easy to control and regulate. Based on this finding, respondents were asked about their attitude towards heating. Results in Figure 6 supported this finding, namely that only $8 \%$ of the respondents quoted that they are not regulating their heating system, which refers to energy conscious attitude.

$35 \%$ of the respondents said that they prefer a constant but acceptable room climate the whole day, according to our opinion due to comfort factors.

Figure 4.

\section{LOHAS characteristics and the role of environmental consciousness}

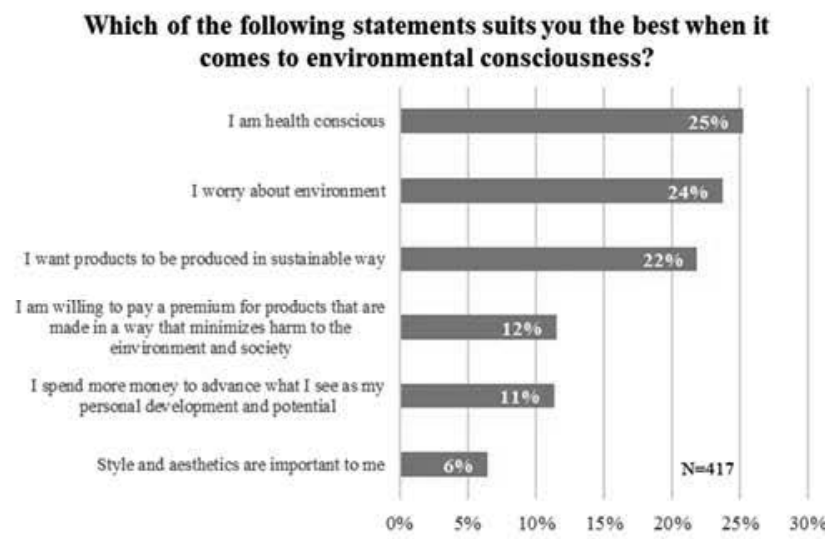

In which part of your life does environmental consciousness prevail?

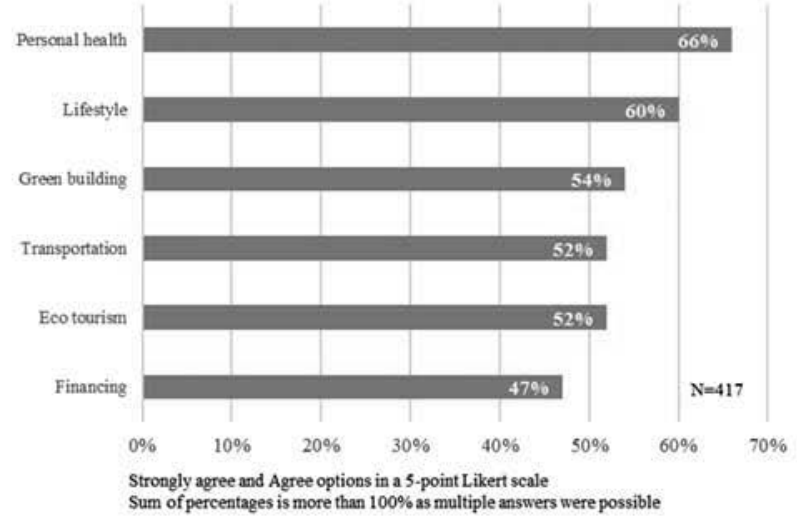




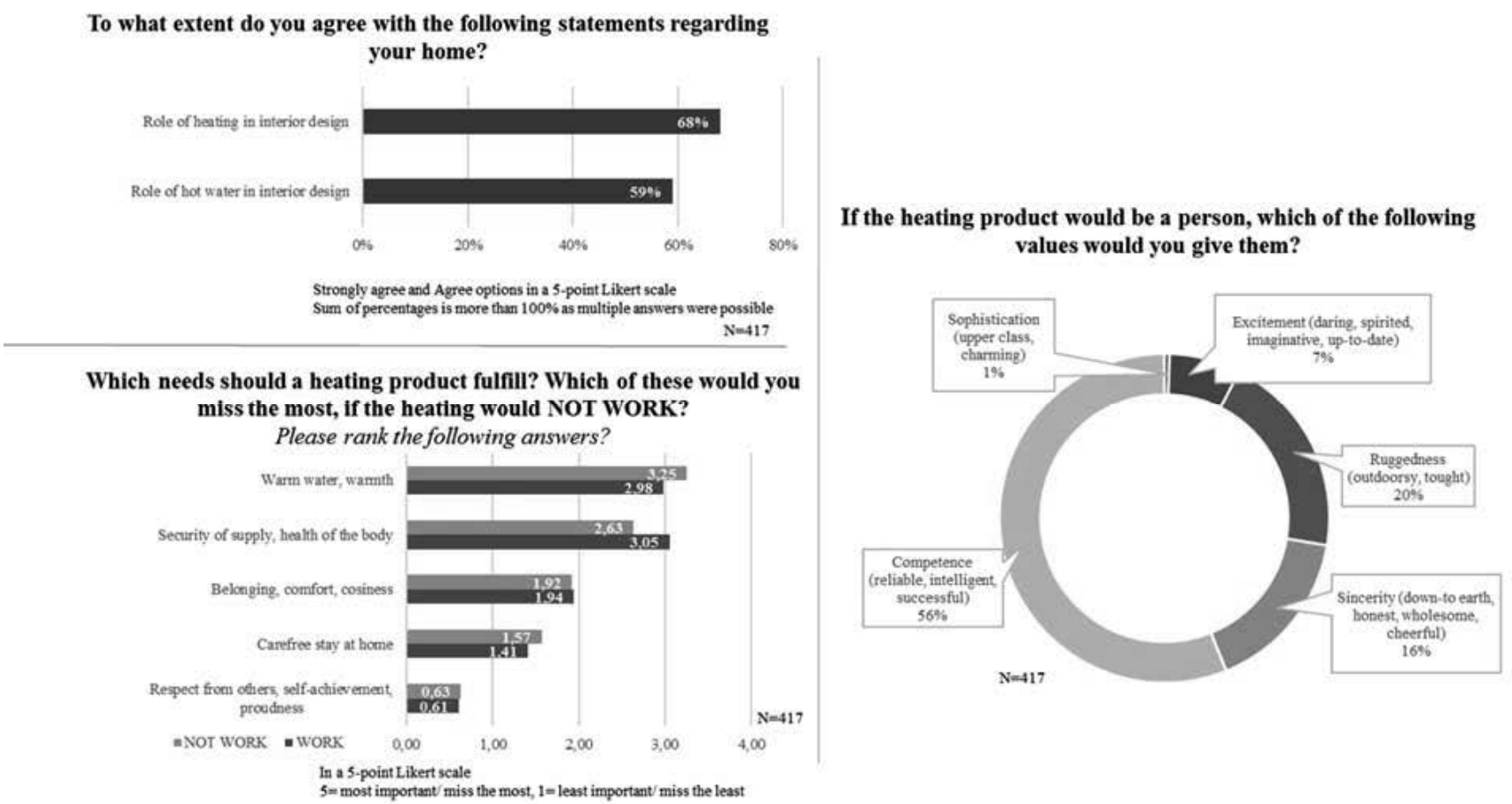

Only the minority ( $8 \%$ of the respondents) said that in their house it is always warm and they hate to freeze, so they probably heat with minimal or no regulation. The majority of respondents (54\%) said that they are only heating when they are at home or only when it is absolutely necessary. According to our opinion, these respondents are driven by financial factors. the majority of the respondents are single and/ or young couples with children in the household. Only a minority of the respondents $(5 \%)$ said that they don't regulate the heating systems at all which corresponds to the energy and cost consciousness of customers.

In the next question group respondents were asked about their motivation to purchase a new heating product.

Heating habits

Figure 6.

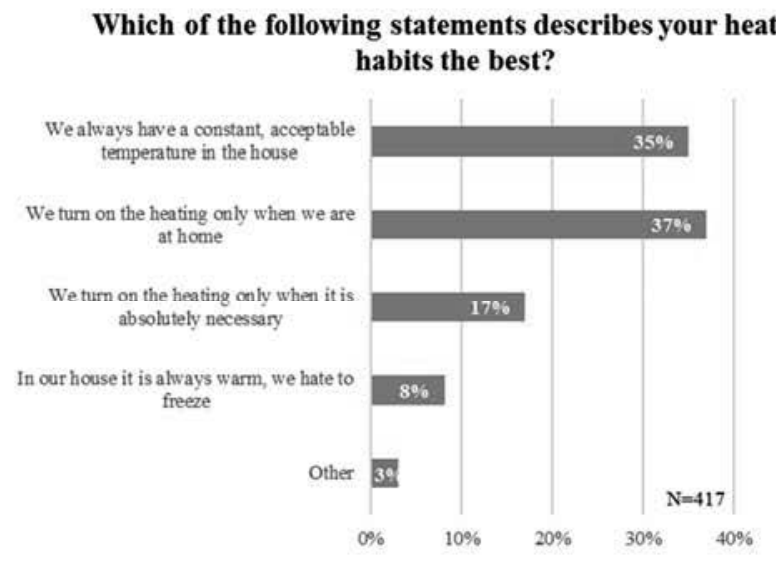

Respondents were asked, who takes over the role for heating regulation in the household. As Figure 6 shows, $95 \%$ of the respondents quoted to regulate the heating system, either themselves or their spouse, which corresponds to the demographical characteristics that
Who is usually regulating the heating system at home?

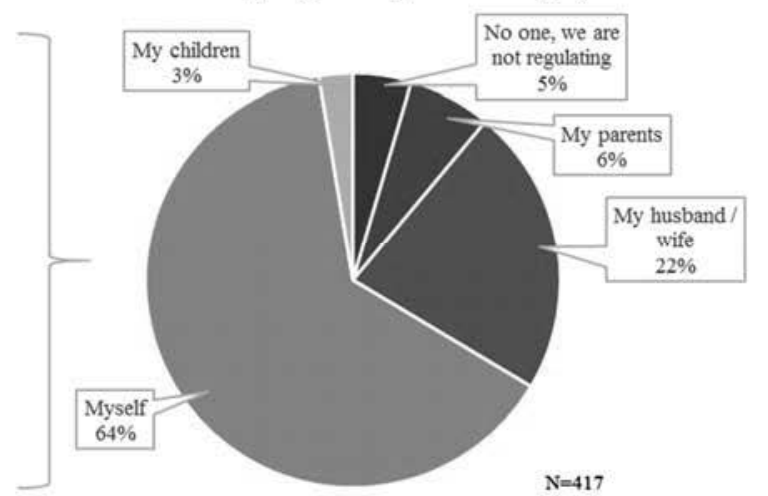

As Figure 7 shows, the quantitative results support the qualitative findings, namely that the end customers are deliberately plan the purchase of heating products, only $8 \%$ of the respondents faced and emergency situation, where immediate purchase was needed. 


\section{Purchase motivation and decision}

What was the reason for buying a new heating product?

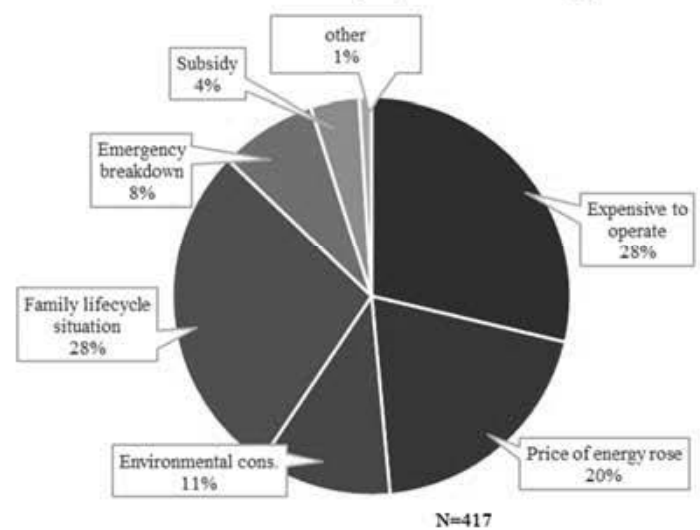

Where did you purchase the product finally?

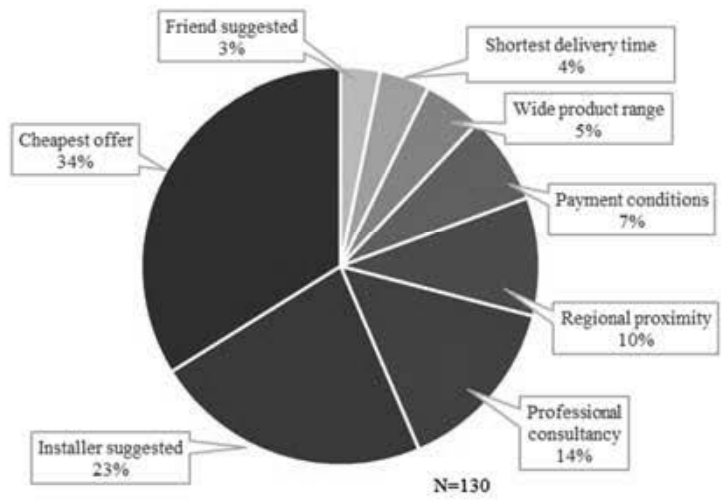

second place, quoted by $23 \%$ of all respondents. Such services as delivery time $(4 \%)$, wide product rage $(5 \%)$ or regional availability $(10 \%)$ were less important factors by choosing the place of purchase. None of the respondents quoted the online shop as the place of the purchase. The low quotation of professional consultancy $(14 \%)$, the suggestion of the social environment $(3 \%)$, or of the suggestion of the installer $(23 \%)$ refers to the ascertainment that the place of the purchase is independent from these influencing information sources and rather the purchase price counts.

Finally, respondents were asked about their past purchase perception and attitude, presented in Figure 8.

Past purchase evaluation: perceived risk, innovation behaviour and involvement

Figure 8 .

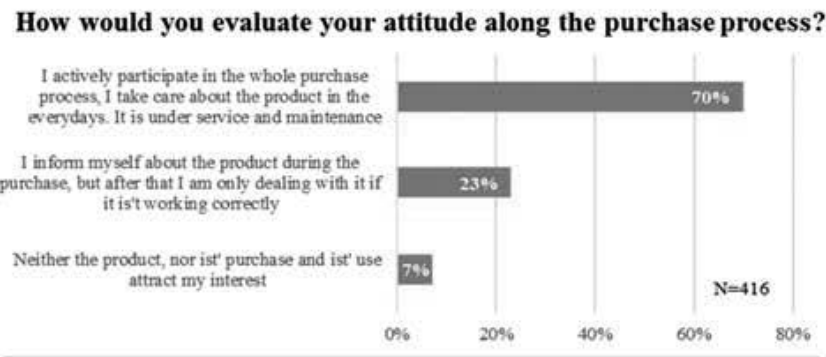

Did you perceive any uncertainty along the purchase process?

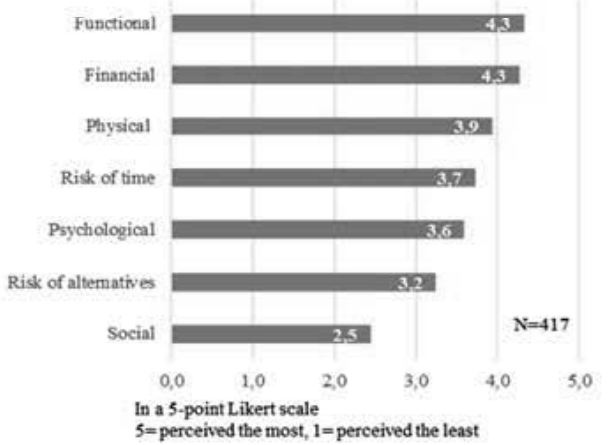

Which of the following statements describe you the best with special regards to heating products?

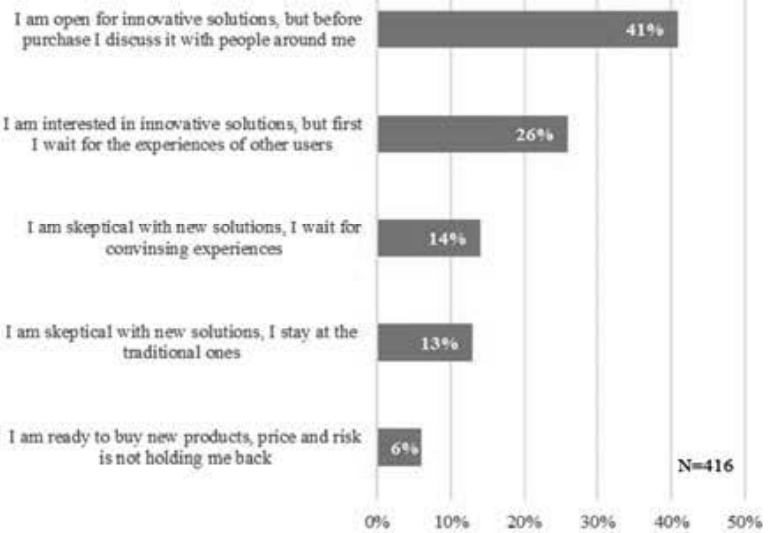


The in-depth interviews showed that end customers actively participated in the purchase process and made a conscious purchase decision, which was supported by the quantitative sample. The majority of the respondents (70\%) quoted that they were active participants of the purchase process and they take care about the product also in the every-days.

Regarding risk perception, respondents agreed to perceive functional and financial risk along the purchase process, furthermore they agreed to perceive rather physical, psychological and time risk. The quantitative sample confirmed the perception of other risk types besides financial and functional risk that respondents perceived with heating products. Nevertheless, social risk was rather not perceived by the participants, which supports the findings of the qualitative questionnaire. Last but not least, participants were asked about how they perceive their innovativeness (no concrete heating technology was named) regarding heating products, presented in Figure $8.41 \%$ of the respondents consider themselves as early adopters, which means that they are open to novel heating solutions but they exchange information with their social environment before the decision-making. A further $40 \%$ of the respondents sees themselves as the early or late majority when it comes to heating products: they are skeptical with novel heating technology; they need convincing experiences of other users. Only the minority sees themselves to be either an innovator $(6 \%)$ or a laggard $(13 \%)$ customer, supposedly due to the high investment and functional costs.

\section{Summary of assumptions and results}

\begin{tabular}{|c|c|c|c|}
\hline & $\begin{array}{l}\text { Assumptions based on the } \\
\text { scientific literature }\end{array}$ & $\begin{array}{l}\text { Key findings of the in-depth } \\
\text { interviews }\end{array}$ & Key findings of the online questionnaire \\
\hline 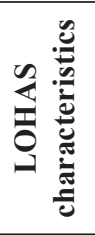 & $\begin{array}{l}\text { Green building plays an im- } \\
\text { portant role in the lives of } \\
\text { the end customers. They can } \\
\text { be described by the LOHAS } \\
\text { characteristics defined by } \\
\text { Cortese (2003). }\end{array}$ & $\begin{array}{l}\text { Environment consciousness prevails } \\
\text { in natural lifestyle, personal health } \\
\text { and green building: conscious ener- } \\
\text { gy consumption, alternative heating } \\
\text { solutions, heating regulation. }\end{array}$ & $\begin{array}{l}\text { Every 4th respondent consider themselves health con- } \\
\text { scious and worry about environment, but there is no } \\
\text { willingness to pay a premium for products that don't } \\
\text { harm environment } \\
\text { The majority agreed that environmental consciousness } \\
\text { prevail in green building }\end{array}$ \\
\hline 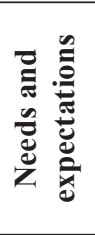 & & $\begin{array}{l}\text { Memories recalled from childhood } \\
\text { that shapes needs and expectations } \\
\text { Personality: similarities to compe- } \\
\text { tence and ruggedness: reliable, trust, } \\
\text { energetic, tough }\end{array}$ & $\begin{array}{l}\text { Need to be fulfilled by a working appliance: security of } \\
\text { supply } \\
\text { Need to be fulfilled in case of breakdown: warmth and } \\
\text { warm water } \\
\text { Heating perceived as a competent, intelligent and suc- } \\
\text { cessful person }\end{array}$ \\
\hline : & & $\begin{array}{l}\text { Warmth in the whole house only at } \\
\text { special occasions, due to high ener- } \\
\text { gy prices }\end{array}$ & $\begin{array}{l}\text { Heating habit: only when necessary and when they are } \\
\text { at home } \\
\text { The most majority is regulating the heating: themselves } \\
\text { or spouse } \\
\text { Heating product plays a role in interior design }\end{array}$ \\
\hline 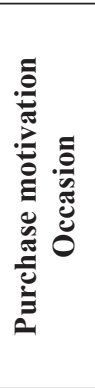 & $\begin{array}{l}\text { Financial factors are the } \\
\text { main underlying motivation } \\
\text { of the purchase. Assumingly } \\
\text { financial factors prevail in } \\
\text { other aspects of the customer } \\
\text { attitude. }\end{array}$ & $\begin{array}{l}\text { Deliberately planned purchase, } 3-6 \\
\text { month long } \\
\text { Need perceived already in the heat- } \\
\text { ing season before } \\
\text { Motivation: rising energy costs in- } \\
\text { creases need for heating renovation } \\
\text { Extension with renewables: invest- } \\
\text { ment must pay off } \\
\text { Conscious, active decision-making, } \\
\text { joint-decision in the family }\end{array}$ & $\begin{array}{l}\text { Deliberately planned purchase } \\
\text { Motivation for purchase: mainly financial factors (old } \\
\text { technology too expensive to operate, rising energy } \\
\text { costs, governmental subsidies) } \\
\text { Environmental consciousness don't motivate customers } \\
\text { for purchase }\end{array}$ \\
\hline 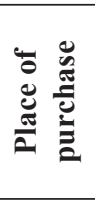 & $\begin{array}{l}\text { End customers purchase in } \\
\text { professional stores or direct- } \\
\text { ly from the installer. Despite } \\
\text { digital purchase preferences, } \\
\text { no online purchase assumed. }\end{array}$ & $\begin{array}{l}\text { Cheapest offer } \\
\text { Where the installer suggested }\end{array}$ & $\begin{array}{l}\text { Cheapest offer } \\
\text { No influence of installer, social environment or other } \\
\text { services, e.g.: shorter delivery time, attractive payment } \\
\text { conditions, excellent service, etc. } \\
\text { Online shop wasn't quoted by any of the respondents }\end{array}$ \\
\hline 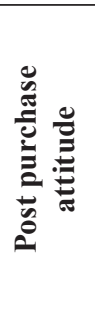 & $\begin{array}{l}\text { End customers perceive } \\
\text { financial risk as they are not } \\
\text { familiar with the complex } \\
\text { technology. Social risk might } \\
\text { be perceived by the adoption } \\
\text { of specific heating technology. }\end{array}$ & $\begin{array}{l}\text { Purchase perceived as complex and } \\
\text { complicated } \\
\text { Perceived functional, financial risk } \\
\text { Situation based involvement }\end{array}$ & $\begin{array}{l}\text { Active participation in the purchase process, high- } \\
\text { involvement in the product use phase } \\
\text { Perceived risk: functional and financial } \\
\text { Rather perceived risk: physical, psychological, risk of } \\
\text { time and alternatives } \\
\text { Not perceived risk: social } \\
\text { Early adopters: exchange in the social environment is } \\
\text { essential before decision }\end{array}$ \\
\hline
\end{tabular}




\section{Discussion}

The goal of our first, explorative research was to investigate the characteristics of the potential end customers of heating manufacturers that former researches treated as a side topic. We found it essential to put the empowered end customers in the focus of the research and to investigate their purchase motivation, needs, expectations and after purchase attitude, independent from any kind of heating technology existing on the heat market. Based on the scarcely available literature, pre-assumptions were made (see theoretical framework), based on which the 2-step research was conceptualized.

Table 2 presents an overview of the pre-assumptions and the key findings of the explorative research.

Both research steps pointed on the fact that respondents are characterized by financial factors in diverse contexts, when it comes to heating products. It prevails in the environmental consciousness, which prevails in diverse fields or respondents' lives but they are not willing to pay a premium for these products. Respondents consciously save money for renovation and for emergency situation around the house, however every second respondent is under financial depth. Financial factors prevail in the heating habits: almost all respondents are regulating their heating system due to high energy prices, only the minority of respondents place convenience factors over economic ones. Furthermore, financial factors are the main underlying motivation for heating renovation: either for extending the existing heating system or to change the boiler. The purchase is perceived as an investment, where the financial advantage (return on investment) must be clear. Despite the fact that financial benefits are important motivators of the purchase, government subsidies don't trigger need for purchase.

Besides economic aspects, functional factors were also mentioned that shape end customer characteristics. Regarding needs and expectations, heating products were found to be fulfilling mainly functional needs and they should fit into interior design (if it is placed in the living space). Respondents perceived a new heating as a reliable, competent and successful person, which refers to the high functional (quality) expectations towards the product. According to our opinion, this means that heating product should work that intelligent and stable that could be customized to specific customer heating habits and should be flexible and easy to regulate with regards to cost effectiveness.

We found an interesting result that end customers could recall information with heating products (technology, fuel) from their childhood with influence their preference for certain heating technologies along the purchase process. According to our opinion this might refer to a learning process that starts in the early age with heating products. We consider this finding a potential further research area concerning the characteristics of a potential end customer of heating products.

Reflecting to the literature overview, we share the view of Stern (1985) in certain aspects. Our results support the characteristic that end customers of heating products are investors, who are looking for long-term benefits by the purchase of heating product. We also found that end customers are expressing their attitudes and values and involve their social environment to exchange information from certain aspects. We also found that end customers perceive diverse types of risks along the purchase process, which also supports the finding of Stern (1985) regarding energy environment decisions that customers plan for long term and want to avoid future problems and inconveniences.

Michelsen et al. (2013) found that end customers are mainly convenience oriented customers, who care more about comfort to sustain their habits over economic factors, as they studied the adoption of innovative heating technologies over conventional ones. We found that financial factors are the most important drivers that prevails in the needs, expectations and underlying motivation of end customers, besides the functional aspects. Furthermore, Michelsen et al. (2013) identified the consequence-aware as the second largest group, who are willing to adopt novel heating technologies based on energy efficiency, which we found one of the least motivating factor by the purchase of a new heating product. According to our opinion, this finding shows that heating technology centered investigation might not be applicable generally to the potential end customer of manufacturers.

\section{Conclusion and recommendations}

We consider this two-step explorative study - presented in the paper - as the first step in the research of end customer characteristics from a marketing managerial approach. The key findings of the empirical research, presented in section 4 and section 5 helped us to get the first insight into the end customer characteristics: needs, expectations and underlying motivation behind customer attitude.

We understood that the purchase process is complex, where end customers are active decision-makers and consciously plan the purchase of a new heating product instead of facing an emergency breakdown. According to our opinion, this is important information for manufacturers as end customers don't purchase unpredictably, but show a heating-season dependent interest and have a lead-time of 3-6 months before the final purchase decision. This means, heating manufacturers have the possibility to get into contact with customers, who are considering to purchase a new heating product in this or in the coming heating season. We think that it is essential for manufacturers to set up an optimal marketing mix by locating the end customers in their purchase process and to apply the appropriate communication channel and the right content of information.

We assume that the information need of a customer, who are open to learn about new heating products is different from the ones that are close to the purchase decision. In order to learn more about this customer segmentation approach, we see the essential the further investigation of end customer purchase attitude and decision-making. Furthermore, it is important to see, 
what are the information and communication channels, influencing contact person that end customers consult along the decision-making process, irrespective of the heating technology end customers might adopt in the future. We see this customer journey-based segmentation approach as a complete new research field in the investigation in end customer attitude towards heating products.

The in-depth interviews with married couples pointed on the importance of relations and the social environment in the decision-making process of heating product. We see this area as potential research field to investigate, in which extent does the social influence prevail along the decision-making process of end customers towards heating products.

Last but not least, the results of the in-depth interviews indicated the diverse degree of involvement end customers perceive along the purchase and use of the heating products. We intend to investigate the question of involvement on a quantifiable sample to make ascertainments on a larger end customer sample.

Regarding the extension of the scientific literature review and the potential theoretical framework building, we consider to analyze other markets where marketers face a similar, 2-step purchase process. We see similarities in the pharmacy industry, where manufacturers produce medication to end customers but sell their products via pharmacists and doctors, who have the responsibility and the power to make recommendations for or against certain products, technologies or brands. Furthermore, we see similarities with the car industry, where manufacturers sell their products via dealers and less directly to the end customers.

\section{References}

Aaker, J. L. (1997): Dimensions of brand personality. Journal of Marketing Research, Vol. 34, p. 347-356.

Achtnicht, M. (2011): Do environment benefits matter? Evidence from a choice experiment among house owners in Germany. Ecological Economics, Volume 70, Issue 11, p. $2191-2200$.

Banfi, S. - Farsi, M. - Filippini, M. - Jakob, M. (2008): Willingness to pay for energy-saving measures in residential buildings. Energy Economics, Vol. 30, p. 503-516.

Bartels, R. - Fiebig, D. G. - van Soest, A. (2006): Consumers and experts: An econometric analysis of the demand for water heaters. Empirical Economics, Vol. 31, pp. 369-391.

Caird, S. - Roy, R. (2008): User-centred improvements to energy efficiency products and renewable energy systems: Research on household adoption and use. International Journal of Innovation Management, Vol. 12, Issue 3, p. 327-355.

Christie, L. - Donn, M. - Walton, D. (2011): The 'apparent disconnect' towards the adoption of energy efficient technologies. Building Research and Information. Vol. 39 , Issue 5, p. 450-458.
Claudy, M. C. - Michelsen, C. - O'Driscoll, A. (2011): The diffusion of microgeneration technologies - assessing the influence of perceived product characteristics on home owners' willingness to pay. Energy Policy, Vol. 39, p. 1459-1469.

Cortese, A. (2003): They care about the world and they shop too. New York Times, published on July 20, 2003, p.3-4. http://www.nytimes.com/2003/07/20/business/ business-they-care-about-the-world-and-they-shoptoo.html?pagewanted=all Access: 10.09.2015.

Creswell, J. W. (2009): Research design - qualitative, quantitative and mixed methods approaches. Los Angeles, London, New Delhi, Singapore: SAGE

Die 20 wichtigsten Megatrends (2008): z-punkt GmbH Foresight Company, Köln/Karlsruhe/ Berlin

Faiers, A. - Neame, C. - Cook, M. (2007): Towards a contemporary approach for understanding consumer behavior in the context of domestic energy use. Energy Policy, Vol. 35, p. $4381-4390$.

Farsi, M. (2010): Risk aversion and willingness to pay for energy efficient systems in rental apartments. Energy Policy, Vol. 38, p. 3078-3088.

Hallin, P-O. (1989): Time for reconversion - adjustment strategies in households in a modified energy situation. Doctoral thesis at the Department on Social and Economic Geography at Lund University. Sweden

Kaplan, A. (1999): From passive to active about solar electricity: innovation decision process and photovoltaic interest generation. Technovation, Vol. 19, p. 467-481.

Kasanen, P. - Lakshmanan, T. R. (1989): Residential heating choices of Finnish households. Economic Geography, Vol. 65, Issue 2, p. 130-145.

Keirstead, J. (2007): Behavioural responses to photovoltaic systems in the UK domestic sector. Energy Policy, Vol. 35, p. 4128-4141.

Kotler, P. (1998): Marketingmenedzsment. Budapest: Müszaki Kiadó

Kotler, P. - Keller, K. L. (2008): Marketingmenedzsment. Budapest: Akadémiai Kiadó

Kwak, S.-Y. - Yoo, S.-H. - Kwak, S.-J. (2010): Valuing energy-saving measures in residential buildings: A choice experiment study. Energy Policy, Vol. 38, Issue 1, p. $673-677$.

Lehota, J. - Horváth, Á. - Rácz, G. (2013): A potenciális LOHAS fogyasztók megjelenése Magyarországon. Marketing \& Management, Vol. 47, Issue 4, p. 36-54.

Lohas Group (2010): www.lohas.com. Access: 27.05.2017.

Mahapatra, K. (2007): Diffusion of innovative domestic heating systems and multi-storey wood-framed buildings in Sweden: Thesis for the degree of Doctor of Philosophy. Östersund: Mid Sweden University

Mahapatra, K. - Gustavsson, L. (2008): An adoptercentric approach to analyse the diffusion patterns of innovative residential heating systems in Sweden. Energy Policy, Vol. 36, p. 577-590.

Mahapatra, K. - Gustavsson, L. (2010): Adoption of innovative heating systems - needs and attitudes of 
Swedish homeowners. Energy Efficiency, Vol. 2010, Issue 3, p. 1-18.

Malhotra, N. K. (2007): Marketing research: An applied orientation. Englewood Cliffs, NJ: Prentice Hall

Mallett, A. (2007): Social acceptance of renewable energy innovations: The role of technology cooperation in urban Mexico. Energy Policy, Vol. 35, Issue 5, p. 2790 -2798 .

Michelsen, C. C. - Madlener, R. (2013): Motivational factors influencing the homeowners' decisions between residential heating systems: An empirical analysis for Germany. Energy Policy, Vol. 57, p. 221-233.

Morris, M. R. - Teevan, J. - Panovich, K. (2010): What do people ask their social networks, and why? A survey study if status message Q\&A behaviour. In Proceedings of CHI, 2010

Nunnally, J. C. (1978): Psychometric theory. New York: McGraw-Hill

Phillips, Y. (2012): Landlords versus tenants: Information asymmetry and mismatched preferences for home energy efficiency. Energy Policy, Vol. 45, p. 112-121.

Qiu, Y. - Colson, G. - Grebitus, C. (2014): Risk preference and purchase of energy-efficient technologies in the residential sector. Ecological Economics, Vol. 107, p. 216-229.

Rauch, C. - Horx, M. (2010): Megatrends Dokumentation. Kelkheim: Zukunftsinstitut GmbH.

Rehman, S. H. - Shareef, A. - Ishaque, A. (2012): Situational and enduring involvement: impact on relationship marketing tactics. Interdisciplinary Journal of Contemporary Research in Business, Vol. 4, Issue 1, p. 598- 605.

Rouvinen, S. - Matero, J. (2013): Stated preferences of Finnish private homeowners for residential heating systems: A discrete choice experiment. Biomass and Bioenergy, Vol 57, p. 22-32.

Scarpa, R. - Willis, K. (2010): Willingness-to-pay for renewable energy: Primary and discretionary choice of
British households for micro-generation technologies. Energy Economics, Volume 32, Issue 1, p. 129-136.

Sernhed, K. (2008): Energy services in Sweden customer relations towards increased sustainability. Doctoral thesis, Division of Efficient Energy Systems, Department of Energy Sciences, Faculty of Engineering at Lund University, Sweden

Sopha, B. M. - Klöckner, C. A. (2011): Renewable and sustainable energy reviews. Vol. 15, p. 2756-2765.

Stern, P. C. (1985): Energy efficiency of buildings: Behavioral issues. Washington, D.C: National Academy Press

Stern, P. C. (2014): Individual and household interactions with energy systems: Toward integrated understanding. Energy Research \& Social Science, Vol. 1, p. 41-48.

Stolyarova, E. - Le Cadre, H. - Osso, D. - Allibe, B. (2015): Stated preferences for space heating investments. Economic Modelling Conference, 15-17. July 15, Boston, United States

Tapaninen, A. - Seppänen, M. - Mäkinen, S. (2009): Characteristics of innovation: a customer-centric view of barriers to the adoption of a renewable energy system. International Journal of Agile Systems and Management, Vol. 4, Issue 1/2, p. 98-113.

Wallace, A. A. - Fleming, P. D. - Wright, A. J. - Irvine, $K$. N. (2010): Home energy efficiency grants and advice: findings from the English Midlands. Local Environment, Vol. 15, Issue 5, p. 403-417.

Wang, J-C. - Chang, C-H. (2013): How online social ties and product-related risks influence purchase intentions: A Facebook experiment. Electronic Commerce Research and Applications, Vol. 12, p. 337-346.

Wilhite, H. - Lutzenhiser, L. (1999): Social loading and sustainable consumption: Advances in customer research, Vol. 26, p. 281-287.

Wüstenhagen, R. - Kaezing J. (2008): Understanding the green energy consumer. Marketing Review St. Gallen, Volume 25, Issue 4, p. 12-16. 